\title{
PROPHYLACTIC TENSION SUTURING IN LAPAROTOMIES FOR GROSS PERITONITIS- A DESCRIPTIVE STUDY
}

\author{
Rao Venkata Srinivasa Rao ${ }^{1}$, Damera Sri Pavani²
}

${ }_{1}^{1}$ Assistant Professor, Department of General Surgery, Maharajah's Institute of Medical Sciences, Vizianagaram, Andhra Pradesh, India. ${ }^{2}$ Senior Resident, Department of Obstetrics and Gynaecology, Maharani Hospital, Andhra Pradesh, India.

ABSTRACT

\section{BACKGROUND}

Burst abdomen is a complication associated with much morbidity and mortality, postoperative to laparotomies. Any measure undertaken to prevent it is laudable and to be followed. There have been many studies as to how to counteract this complication.

This study aims to have evidence on prophylactic retention suturing in cases of gross peritonitis, so as to prevent abdominal wound dehiscence.

\section{MATERIALS AND METHODS}

This study was carried out for a period of two years in a setting of tertiary hospital. Patients presenting with various causes of gross peritonitis were grouped as an interventional group and subjected to the intervention. The rate of wound dehiscence, evisceration leading to reoperation was enumerated and tabulated. Along with it, incidence of incisional hernia was also studied.

\section{RESULTS}

In this study, it was found that retention sutures or tension sutures in laparotomies done for gross peritonitis could reduce potential complications like wound infection, incisional hernia, wound dehiscence etc., which were almost negligible in patients who underwent tension suturing.

\section{CONCLUSION}

Prophylactic retention suturing is a thing to be followed as a routine for all high-risk group of patients with potential wound dehiscence.

\section{KEY WORDS}

Abdominal Wound Dehiscence; Laparotomy; Evisceration; Wound Infection; Incisional Hernia; Tension Suturing.

HOW TO CITE THIS ARTICLE: Rao RVS, Pavani DS. Prophylactic tension suturing in laparotomies for gross peritonitis- a descriptive study. J. Evolution Med. Dent. Sci. 2018;7(26):3064-3066, DOI: 10.14260/jemds/2018/687

\section{BACKGROUND}

Abdominal wound dehiscence (or) burst abdomen is a most serious post-operative complication for laparotomies and is associated with high mortality and morbidity. It occurs in 0.4 to $3.5 \%$ of major abdominal surgeries. This condition is not only a distress to the patient, but can also result in evisceration and necessitate reoperation. It increases treatment cost and is a waste of hospital resources. Despite advancement in operation technique and risk control methods during recent years, the complication of burst abdomen continues to be a major problem. With advancement of techniques the incidence of burst abdomen came down in elective laparotomies, but in cases of emergency laparotomies particularly in cases of peritonitis this complication rate is high. However, considering the pain and morbidity, no benefits were observed that justify the use of retention sutures as a routine method for laparotomies. The purpose of this study was to evaluate the effect of prophylactic retention suturing in laparotomies for gross peritonitis, which was one of the high risks for wound dehiscence in patients who underwent midline laparotomies.

'Financial or Other Competing Interest': None.

Submission 03-04-2018, Peer Review 09-06-2018,

Acceptance 15-06-2018, Published 25-06-2018.

Corresponding Author:

Damera Sri Pavani,

C/o. Dr. K. N. Manohar,

FF-2, Visakha Heights, 100FT Ring Road,

Vizianagaram, Andhra Pradesh, India

E-mail: raosrinu.srinu@gmail.com

DOI: $10.14260 /$ jemds $/ 2018 / 687$

\section{(c) $(1) \ominus$}

\section{Aims and Objectives}

The aim of this study was to subject a group of patients presenting with gross peritonitis with emergency laparotomy as the intervention, to tension suturing and to know the results in terms of wound dehiscence. As a result of this study, the conclusion intended would be-

- A study of a group of patients subjected to emergency laparotomies with tension suturing and the rate of complications. No comparisons were done in this study.

\section{MATERIALS AND METHODS}

This is a descriptive study for a period of two years from August of 2014 to 2016. This study was undertaken over the patients presenting to General Surgical OPD and Emergency Department at Maharajah Institute of Medical Sciences, Vizianagaram, Andhra Pradesh. All those patients diagnosed of peritonitis and planned for emergency laparotomy were included in this study. At the time of inclusion of the patient into the study, a detailed and informed consent was taken. Every patient was subjected to the requisite investigations and followed up.

The whole sample was subjected to basic clinical evaluation and were diagnosed based on the clinical findings and erect abdomen x-ray and USG consecutively enrolled. 30 cases were included in this study.

Type of Study

Descriptive Study.

\section{Study Period}

Two years from August of 2014 to 2016. 


\section{Study Subjects}

Patients presenting to General Surgical OPD and emergency department diagnosed of peritonitis and planned for emergency laparotomy.

\section{Study Setting}

Tertiary Hospital, Nellimarla, Vizianagaram.

\section{Inclusion Criteria}

1. Patients undergoing midline laparotomy for gross peritonitis.

2. Age $>18$ yrs.

3. Incision $>10 \mathrm{cms}$.

4. Patients willing to participate in the study.

\section{Exclusion Criteria}

1. Patients with comorbidities.

2. Patients with a life-risk due to neglected peritonitis.

3. Patients who are lost for follow-up.

\section{Intervention}

In the intervention fascia was sutured continuously using 1-0 prolene; located $1 \mathrm{~cm}$ from the edge of linea alba incision. The continuous suture was locked every $5 \mathrm{~cm}$ to divide the long continuous suture into multiple small sections. Skin and subcutaneous tissue was sutured using 2-0 nylon interrupted suturing as was routinely done.

However, in this study tension sutures or fascial retention sutures were added before closure of linea alba, which contains $5 \mathrm{~cm}$ of skin, subcutaneous tissue, rectus muscle and abdominal fascia (except peritoneum) on each side of midline. The first retention suture was placed $5 \mathrm{~cm}$ above the lower end of incision and repeated every $5 \mathrm{~cm}$ towards the upper end of incision. Each suture is covered with a piece of transfusion set tubing to prevent cut through.

Occurrence of wound dehiscence was assessed by the examination of wound. If there was any discharge from sutured site, the corresponding skin sutures were removed, and digital examination was performed to assess the integrity of the fascia. In cases of clinical dilemma, ultrasonography was done.

Microsoft Excel was used to tabulate and categorise.

\section{RESULTS}

20 patients were consecutively studied in this study.

\begin{tabular}{|c|c|}
\hline Sex & No. of Patients \\
\hline Male & 27 \\
\hline Female & 3 \\
\hline Total & 30 \\
\hline \multicolumn{2}{|c|}{ Table 1. Sex ofthe Patients } \\
\hline
\end{tabular}

\begin{tabular}{|c|c|}
\hline Cause & No. of Patients \\
\hline Ruptured appendix & $15(50 \%)$ \\
\hline Duodenal perforation & $9(30 \%)$ \\
\hline $\begin{array}{c}\text { Intestinal obstruction with } \\
\text { bowel gangrene }\end{array}$ & $1(3.33 \%)$ \\
\hline Ileal perforation & $5(16.67 \%)$ \\
\hline Total & $\mathbf{3 0}$ \\
\hline \multicolumn{2}{|c|}{ Table 2. Cause of Peritonitis } \\
\hline
\end{tabular}

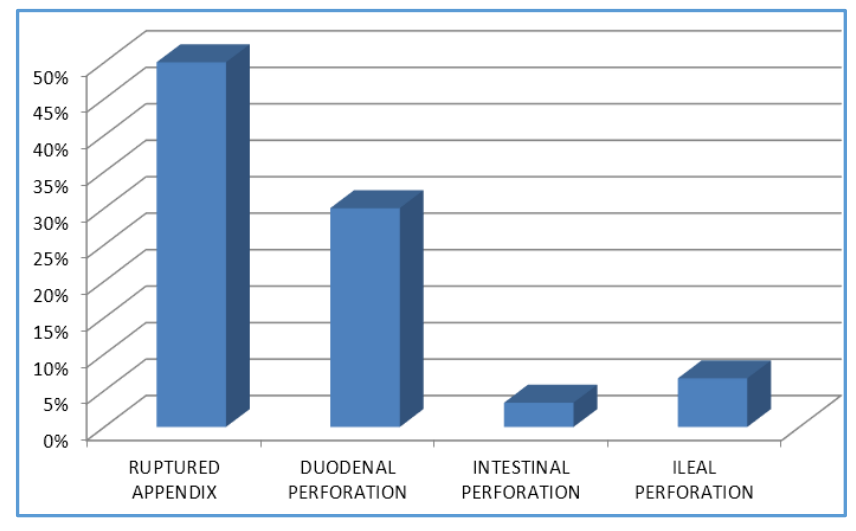

Figure 1

\begin{tabular}{|c|c|}
\hline Complication & No. of Patients \\
\hline Wound dehiscence & 1 \\
\hline Evisceration & NIL \\
\hline Re-operation & NIL \\
\hline Wound infection & 2 \\
\hline Incisional hernia & 9 \\
\hline Total & 12 \\
\hline
\end{tabular}

(Some patients had two complications simultaneously).

\begin{tabular}{|c|c|}
\hline & No. of Patients \\
\hline Major & NIL \\
\hline Minor & 1 \\
\hline Total & 1 \\
\hline \multicolumn{2}{|c|}{ Table 4. Wound Infection } \\
\hline
\end{tabular}

\begin{tabular}{|c|c|}
\hline Defect Size & No. of Patients \\
\hline Full length of incision & 1 \\
\hline$>$ Half of the length of incision & 3 \\
\hline$<$ Half of the length of incision & 5 \\
\hline Total & 9 \\
\hline \multicolumn{2}{|c|}{ Table 5. Incisional Hernia } \\
\hline
\end{tabular}

All patients with incisional hernia were repaired by Hernioplasty using Prolene Mesh by Inlay technique. No postoperative complications occurred after hernioplasty.

\begin{tabular}{|c|c|}
\hline POD & No. of Patients \\
\hline 1 & 9 \\
\hline 2 & 9 \\
\hline 3 & 7 \\
\hline 4 & 7 \\
\hline 5 & 4 \\
\hline 6 & 4 \\
\hline 7 & 4 \\
\hline \multicolumn{2}{|c|}{ Table 6. Grading of Pain by VAS } \\
\hline
\end{tabular}

\section{DISCUSSION}

Laparotomy wound dehiscence has remained a puzzle over many years. Most surgeons globally have achieved and maintained failure rates well below $1 \%$. This however has not deterred continuing research in attempts to eliminate the problem. ${ }^{1}$

Simek and Danek described the use of intraperitoneal resorbable mesh to prevent wound dehiscence. ${ }^{2}$

Graham DJ et al in USA wrote that intra-abdominal infections increase wound dehiscence significantly. ${ }^{3}$ MacBurney, Kern and Johnson published reduction in their 
infection rates after the use of rubber gloves introduced by Halstead. Paul Mikulicz is known to have changed gloves every two hours to keep infection rate low. 4

Wound dehiscence, eviscerations and incisional hernias have associated with midline abdominal incisions in any age group. ${ }^{5}$ Sloan, in his research found that tension across a vertical incision is 30 times more than across a transverse incision. ${ }^{6}$

Though drains are routinely used, Neuter opposed to the idea stating that they act as foreign bodies leading to various complications.

Excessive injury to tissues with decreased tissue respect might also be a cause of infection and various complications. Introduction of diathermy knife by Kelly (1926) has reduced excessive clamping of tissues. ${ }^{7}$

Tension sutures are used for gross peritonitis by surgeons who advocate it to "belt and brace" layered abdominal closures. ${ }^{8}$

According to a study by Agarwal et al on comparing the incidence of burst abdomen in cases operated by continuous suture technique and by RTL the p-value was found to be 0.0026 , which is highly significant. On analysis of the incidence of burst abdomen in cases having a grade II intraabdominal pressure, the p-value was found to be 0.0009 which is highly significant. Closure of midline incision by RTL reduces the incidence of burst abdomen. ${ }^{9}$

The strengths of the study with various complications have been dealt separately, though they belong to the same spectrum.

Limitations being comparison between different techniques of suturing and tension suturing was not dealt with in this study. There is a plain evidence for advantages of retention suturing over routine continuous suturing. A degree of human error is always possible.

\section{CONCLUSION}

$85 \%$ of the patients included under this study were males. Causes of gross peritonitis included ruptured appendix in $50 \%$, duodenal perforation in $30 \%$, ileal perforation in $16.67 \%$ and bowel gangrene in $3.33 \%$. The various postoperative complications considered were wound dehiscence, evisceration and reoperation, wound infection and incisional hernia. Though all the complications considered here are a part of the same spectrum, for convenience, study patients were divided into different categories.
Incisional hernia was found to be full length of the incision in $11.11 \%$ of the patients, more than half the length of the incision in $33.33 \%$ and less than half in $55.55 \%$.

This study only throws a light on the various possible complications after tension suturing for gross peritonitis. These results could serve as a platform of raw data for a major study comparing the outcomes of a routine abdominal closure in layers.

One of the patients who underwent tension suturing developed wound dehiscence, which was statistically not significant.

The end note for this study is that prophylactic retention suturing is a good practice in all high-risk group of patients with potential for wound dehiscence.

The sample size is small due to the rarity of the condition.

\section{REFERENCES}

[1] Smith JAR. Complications: prevention and management. Clinical surgery in general. $3^{\text {rd }}$ edn. Edinburgh: Churchill Livingstone 1999: p. 350.

[2] Simek K, Danek T. Prevention and therapy of dehiscent laparotomy wounds. Rozhledy Chirugii (Czech Republic) 2000;79(10):495-7.

[3] Graham DJ, Stevenson JT, McHenry CR. The association of intra-abdominal infection and abdominal wound dehiscence. American Journal of Surgery 1998;64(7):660-5.

[4] John AS. Advances in knowledge related to wound repair and healing. Annals of Surgery 1984;201: p. 268.

[5] Makela JT, Kiviniemi H, Juvonen T, et al. Factors influencing wound dehiscence after midline laparotomy. American Journal of Surgery 1995;170(4):387-90.

[6] Jorgenson EJ, Smith ET. Postoperative Abdominal wound separation and evisceration. American Journal of Surgery 1950;79(2):282-7.

[7] Suman KD. Wound healing, operative incision and skin grafts. In: Hardy JD, edr. Hardy's Textbook of surgery. $2^{\text {nd }}$ edn. JB Lippincott Company, 1992: p. 115.

[8] Nicholls MWN. Wound infection. Bailey and Love's Short practice of surgery. 21st edn. Chapman and Hall 1991: p. 81.

[9] Agarwal A, Hossain Z, Agarwal A, et al. Reinforced tension line suture closure after midline laparotomy in emergency surgery. Trop Doct 2011;41(4):193-6. 